From the Department of Child Health, Medioal School, University of Indomesia, Jakarta.

\title{
Corticosteroid and Immunosuppressive Treatment in Glomerulonephritis (Literature Review)
}

by

\section{H. Alxtas}

During the past decades corticosteroids and immunosuppressive agents are widely used in the treatment of glomerulonephritis, based on the assumption that many forms of glomerular diseases have an immunologic basis (Dixon, 1968).

Acute and chronic toxicity produced by these drugs justifies the physician to know exactly about the natural history of the disease. Since the use of closed renal biopsy technique and the study of tissue by electrone microscope and immunofluorescent method, it has become clear that glomerulonephritis does not represent a single homogenoes entity.

Current classification used in many centres is presented in table 1 , which to some extent could be used by the clinician to predict the prognosis and response to treatment and also as a guide to make a controlled therapeutic study.

Received 12th. August, 1974.
On this occasion we would only review glomerulonephritis which is not associated with systemic diseases like Schönlein Henoch purpura, Systemic lupus erythematosus etc.

Table 1: Classification of primary glomerulonephritis.

1. Minimal changes.

2. Focal Glomerulosclerosis.

3. Proliferative Glomerulonephritis.

4. Membranous Nephropathy.

5. Advanced Chronic Glomerulonephritis.

\section{Minimal changes.}

The glomeruli in this type show no abnormalities or onily slight increase of mesangial matrix or slight focall hypercellularity. Electrone microscopic examination reveals unspecific fusion of the epithelial foot processes. No immune complex depasit is detected on fluorescence microscopy. 
The clinical manifestation is usually a pure nephrotic syndrome, but sometimes only proteinuria. Microscopic hematuria, temporary hypertension and slight B.U.N. and creatinine elevation are rarely detected.

Progression to chronic renal failure is unusual (Hayslett, 1969). Differential protein clearance usually shows a highly selective pattern (Cameron, 1968).

Minimal change is found in $77 \%$ of nephrotic syndrome in children, in contrast to only $18 \%$ in adults (Churg, 1970; Robson, 1971). Our own series in children showed only $45-46 \%$ (Kasim, 1971; Wila Wirya, 1974).

Retrospective comparisons of the effect of treatment in nephrotic syndrome in children show an improvement in the survival of the treated patients.

The mortality rate before the sulfonamid-era was $67 \%$, after the invention of Penicillin $35 \%$ and after the use of corticosteroid only $9 \%$ (Arneil, 1971).

Almost all minimal change nephrotic syndromes were steroid sensitive $(94-97 \%)$ (Churg, 1970; White, 1970). Besides the histological picture, steroid sensitivity could also be predicted from the protein clearance examination.

Patients with high selective protein clearance are usually steroid sensitive, whereas non-selective clearance are usually resistant to steroid medication (Cameron, 1968). Smith (1972) also put forward other clinical signs which usually could give guidance to sterouid resistance, i.e. : significant hematuria, persistent hypertension, persistent azotemia.

The steroid dosage used in the treatment of nephrotic syndrome in children as recommended by the In. ternationall Collaborative study of renal diseases in children (Arneil, 1971) is as follows: $60 \mathrm{mg} / \mathrm{m}^{2} /$ day given daily for 4 weeks, followed by another 4 weeks of intermittent prednisone given for three consecutive days out of seven with a dosage of 40 $\mathrm{mg} / \mathrm{m}^{2} /$ day. Patients who become protein-free during this period are designed as "responders" or "sensitive", whereas those who do not, are ,nonresponders" or "steroid resistant".

Although minimal change mostly responds to steroid on initial treatment, about $37-93 \%$ show no stable remission (Churg, 1970; White, 1970). Sooner or later they show relapse of the disease.

In the majority this can be overcome by further steroid treatment. In some others relapses are so frequent that the dosage of steroid required produces severe toxic effects.

Reports are accumulating that this so-called "frequent relapsers" minimal change could be influenced by Cyclophosphamide (Endoxan) tre- 
atment (Barratt, 1971; Chiu, 1973). A double blind study showed that after treatment of 8 weeks cyclo. phosphamide, the frequent relapsers were significantly reduced, compared with the control group (Barratt and Soothill, 1970).

The Cyclophosphamide treated group showed only $20 \%$ relapses against $73 \%$ in the control group after 16 weeks and $20 \%$ against $90 \%$ relapses after 60 weeks cessation of therapy.

Also in steroid resistant minimal lesion nephrotic syndrome Drummond (1969) reported remission in 9 out of 11 cases.

Leucopenia does not correlate with the optimal therapeutic effect as it was formerly thought (Cameron, 1970). A combination with low dosage steroid is preferable to combat its side-effect on the bone marrow (Barratt and Soothill, 1970).

The recent report of azospermila in adult (Fairley, 1972) and itesticular atrophy in a child in autopsy (Hyman, 1972) and also amenorrhoea in females (Fairley, 1972) has brought much limitation in the further use of Cyclophosphamide in steroid dependent patients.

In view of the side-effects the International Study Group (I.S.G.) has discontinued trials with Cyclophosphamide. An international workshop on Cyclophosphamide concluded some recommendations concerning the further use of this drug as follows: In steroid responder frequent relap- ses nephrotic syndrome Cyclophosphamide should only be given when unacceptable steroid toxicity has occured. The second course should also be considered when toxicity or resistance develops. The dose and duration of treatment should not exceed $2-3 \mathrm{mg} / \mathrm{kg} . \mathrm{BW} /$ day for $60-$ 80 days.

Azathioprine (Imuran) was in the beginning sporadically reported showing benefit in nephrotic children (Alatas, 1972; Lagrue, 1971). A controlled trial conducted by the I.S.G. however, failed to show a significant beneficial effects either in steroid resistant or in frequent relapser nephrotic syndrome (Abramowicz, 1971).

Chlorambucil (Leukeran) at a dose of $0,1-0,2 \mathrm{mg} / \mathrm{kg}$. BW/day appears to be effective to induce prolonged remission in steroid sensitive frequent relapser patients (Grupe, 1973).

A controlled study showed no relapse in patients treated with chlorambucil and prednisone, whereas many relapses were noted in the group treated with prednisone allone in a follow up period of 20 months (Grupe, 1973).

\section{Focal Glomerulosclerosis.}

Sclerosis of the glomeruli is dis tributed focally and segmentally in this group. Post-mortem study shows that it begins in the juxtamedullary region and gradually spreads outwards (Rich, 1957). This is the rea- 
son why it is often missed in the first biopsy or often described as "minimal change".

Fluorescence microscopy reveals focal IgG, IgM, beta-1-C globulin deposit in the sclerosed area.

The clinical manifestation is usually a nephrotic syndrome or proteinuria/ hematuria. Habib (1970) reported that this lesion shared multiple clinical features such as steroid resistance or dependence, early onset of hypertension and renal insufficiency, microscopic hematuria and poorly selective proteinuria.

A lasting response to corticosteroid therapy was never observed (Cameron, 1972; White, 1970) and in the majority of cases the disease progressed to chronic renal failure $(\mathrm{Ha}$ bib, 1970; Cameron,1972).

Three of the 7 deaths in the I.S.G. report of nephrotic syndrome in children belonged to this group (Abramowicz, 1970).

3. Proliferative Glomerulonephrithis.

The I.S.G. has classified this group into 5 subgroups as follows:

a. Diffuse exudative.

The histological picture shows mesangial and endothelial cell proliferation with infiltration of leucocytes.

Electron and fluorescence microscopy reveals subepithelial deposit ("humps") of IgG, complement and fibrinogen in a granular pattern. This form occurs mainly in poststreptococcal glomerulonephritis. Be- sides the beta-hemolytic streptococcus found on throat culture examination or elevation of anti sitreptalysin titer-O, the beta-1-C globulin is also temporarily depressed in the acute stage of the disease.

Posit-streptococcal nephritis has a benign coarse in children. No specific treatment is needed in this group. Prospective study of 60 children (Travis, 1973) revealed only $2 \%$ of progression, in a follow up period of 3 - years.

b. Mesangial.

Diffuse mesangial proliferation is the only abnormality found in this group. The hisitological picture is very similar to that of patients with resolving post-streptococcal glomerulonephritis (Ghurg, 1970). The clinical picture reveals either proteinuria or nephrotic syndrome with microscopic hematuria. Hypertension is seldom detected. Habib (1970) put forward that patilents with persistent nephrotic syndrome had a bad prognosis.

\section{c. Focal.}

This lesion occurs mainly in nephritis complicating a systemic disease such as Bacterial Endocarditis, Schönlein Henoch purpura or Systemic lupus erythematosus. In other cases of focal lesion no specific cause could be detected.

The histological picture represents a focal and segmental distribution of mesangial/endothelial cell proliferation, which may resolve completely or 

PHRITIS

may persist without noticable improvement or deterioration. The finding of IgA, IgG deposit represen's a good prognosis (Maintz, 1972).

Focal lesions are frequently associated with recurrent or persistent hematuria or resemble an acute glomerulonephritis.

The clinical course was usually benign. No death was reported in $\mathrm{Ha}$ bib's (1970) or Heptinstall's (1966) series.

Treatment with potentially dangerous drugs are not justifies and should be avoided.

\section{d. Crescent.}

Crescent is a proliferation of the parietal epithelium of the Bowman capsule.

Habib divided (1970) this group into 3 parts. Type III with crescent formation of more than $80 \%$ has the worse prognosis. It is usually designe as rapidly progressive glomerulonephritis (RPGN) and formerly called "subacute glomerulonephritis".

Immunofluorescence microscopy reveals intense fibrinogen deposit with characteristic linear deposit of IgG along the basement membrane. The clinical picture is usually an acute glomerulonephritis with early onset of oliguria, but could also be presented as a nephrotic syndrome.

Anti streptolysin titer and beta-1-C globulin was usually normal. Heptinstall (1966) discussed the lack of streptococcal aetiology in this group.
Rapid deterioration to terminal renal failure in a couple of months was usually the rule (Habib, 1970; Cameron, 1972).

The report of Kincaid-Smith et al. (1968) and Arieff (1972) obtaining better results with a combination of corticositeroid and anticoagulants should require further judgement with controlled trial for ultimate assessment.

\section{e. Membrano-proliferatlive glomeru-} lonephritis (MPGN).

Under the light microscope the glomeruli appear enlarged, lobullaied hypercellular with thickening of the basal membrane.

Dense deposit perhaps representing antigen-antibody complexes on the endothelial side of the basement membrane is seen on electrone microscopy. Fluorescent staining demonstrates deposit of beta-1-C globulin in a nodular pattern along the capillary loops. IgG is less frequently present. MPGN ils mostly found in adolescent or preadolescent age, but may effect younger or older children. The clinical manifestation could be gross hematuria, with or without proteinuria or nephrotic syndrome Persistent serum complement (beta1-C globulin) depression is present in most cases (Cameron, 1970).

Persistent hypertension frequently develops. The clinical course usually progresses into chronic renal failure. Cameron (1973) put forward that patients developing a full nephrotic 
syndrome at some time in their disease are markedly worse $(70 \%$ survival at 5 years and $30 \%$ survival at 10 years) than those who show only persistent moderate proteinuria or recurrent hematuria ( $90 \%$ survival at 5 and 10 years).

Cyclophosphamide, prednisone and Azathioprine alone or in combination does not seem to influence the course of the disease (Cameron, 1970).

\section{Membranous Nephropiathy.}

The histological picture shows thickening of the basal membrane without cell proliferation. Subepithelial deposits are detected in electron microscopy which seem to be fine granular deposits of IgG and beta-1-C globulin on fluorescence microscopy. On silver staining a typicall "spikes" appearance can be detected at the early stage of the disease. Three/ four stages of the disease based on the histological appearance are wricten in the literature (Habib, 1973; Gluck, 1973).

Though usually found in adults, $\mathrm{Ha}$ bilb (1973) reported 50 cases in children including infants.
The clinical manifestation is frequent ly a nephrotic syndrome associated with hematuria. It is often latent and discovered only by routine urinalysis.

Besides a pro and contra opimion on the benefit of steroid therapy (Rastogi, 1969; Gluck, 1973), remission often occurs while partients received no treatment (Habib, 1973).

A controlled trial comparing the effect of corticosteroid to combined treatment of steroid and Azathioprine showed no statilstically significant difference in the mean proteinuria or creatinine clearance in treatment and control groups. (Med. Research Council, 1971).

Cyclophosphamide was also reported to be of no effect in this type of lesion (Gluck, 1973).

\section{Advanced chronic glomerulone-} phritis.

This is the end stage of any progressive glomerulonephritis. The glomerulosclerosis is so advanced that differentiation is not more possible.

\section{REFERENCES}

1. ABRAMOWICZ, M., ARNEIL, G.C., BARNETT, H.L., BARRON, B.A., EDELMANN, C.M., GORDILLO-P.G., GREIFER, I., HALLMAN, N., KOBAYASHI, K.O. and TIDDENS, H.A. : Controlled trial of Azathioprine in children with the nephrotic syndrome. Lancet 1 : 959 (1970).
2. ALATAS, H., WILA WIRYA, I.G.N. and SUTEDJO: Treatment of Childhood Nephrotic Syndrome with Imuran. Paediatr. Indones. 12 : 363 (1972).

3. ARIEFF, A.I. and PINGGERA, W.F.: Rapidly progressive glomerulonephritis treated with anticoagulants. Arch. intern. Med. 129 : 77 (1972). 
4. ARNEIL, G.C.: The nephrotic syndrome. Pediat. Clin. N. Amer. $18: 547$ (1971).

5. BARRATT, T.M.: Cytotoxic Agents in Childhood glomerulonephritis. Arch. Dis. Child. 47 : 159 (1972).

6. BARRATT, T.M. and SOOTHILL, J.F: Controlled trial of cyclophosphamide in steroid-sensitive relapsing nephrotic syndrome of childhood. Lancet $2: 479$ (1970).

7. CAMERON, J,S.: Histology, protein clearance and response to treatment in the nephrotic syndrome. Brit. med. J. 4 : 352 (1968).

8. CAMERON, J.S.: The Natural History of Glomerulonephritis in Rena] Disease. 3rd ed. (Blackwell, London 1972).

9. CAMERON, J.S., GLASGOW, E.F.. OGG, C.S. and WHITE, R.H.R.: Membranoproliferative Glomerulonephritis and Persistent Hypocomplementemia. Brit. med. J. 4 : 7 (1970).

10. CAMERON, J.S., OGG, C.S., WHITE, R.H.R. and GLASGOW, E.F.: The clinical features and prognosis of patients with normocomplementemic mesangiocapillary glomerulonephritis. Clin. Nephrol. 1 : 8 (1973).

11. CHIU, J., MeLAINE, P.N. and DRUMMOND, K.N.: A controlled prospective study of cyclophosphamide in relapsing, corticosteroid-responsive, minimal lesion nephrotic syndrome in childhood. J. Pediatr. 82 : 607 (1973).

12. CHURG, J., HABIB, R. and WHITE, R.H.R.: Pathology of the nephrotic syndrome in children. Lancet, $1: 1299$ (1970)

13. DIXON, F.J.: The pathogenesis of glomerulonephrities. Amer. J. Med. 44 : 493 (1968).

14. DRUMMOND, K.N. : Treatment with cyclophosphamide of resistant and relapsing nephrosis in childhood. Proc. 4th Int. Congr. Nephrol. Stockholm 3 : 72 (1969).

15. FAIRLEY, K.F.. BARRIE, J.U. and JOHNSON, W.: Sterility and testicular atrophy related to cyclophosphamide therapy. Lancet 1 : 568 (1972).

16. GLUCK, M.C., GALLO, G., LOWENSTEIN, J. and BALDWIN, D.S.: Membranous glomerulonephritis. EvaIuation of clinical and pathologic features. Ann. intern. Med. 78 : 1 (1973).

17. GRUPE, W.E.: Chlorambucil in a controlled study of steroid dependent nephrotic syndrome. Pediatr. Res. 7 : 413 (1973).

18. GRUPE, W.E.: Chlorambucil in steroid dependent nephrotic syndrome. J. Pediatr. 82 : 598 (1973).

19. HABIB, R.: Classification anatomique de nephropathies glomerulaires. Pädiatr. Fortbildk. 28 : 3 (1970).

20. HABIB, R., KLEINKNECHT, C. and GUBLER, M.G.: Extramembranous glomerulonephritis in children. Report of 50 cases. J. Pediatr. $82: 754$ (1973).

21. HAYSLETT, J.P., KRASSNHER, L.S. BENSCH, K.G., KASHGARIAN, M. and EPSTEIN, F.H.: Progression of lipoid nephrosis to renal insufficiency. New Eng. J. Med. 281 : 181 (1969).

22. HYMAN, L.R. and GIIBERT, E.F. : Testicular atrophy in a prepubescent male after cyclophosphamide therapy. Lancet $2: 426$ (1972).

23. HEPTINSTALL, R.H.: Pathology of the Kidney. Boston, 1966.

24. KASIM, J.A., HIMAWAN, S. and WILA WIRYA, I.G.N.: Renal biopsy in children with nephrotic syndrome. A morphological study. Paediatr. Indones. 12 : 55 (1972).

25. KINCAID-SMITH, P., SAKER, P.M. and FAIRLEY, K.F.: Anticoagulants in irreversible renal failure. Lancet 2 : 1360 (1968). 
26. LAGRUE, von G. und BARIETY, J.: Immun suppressive Langzeitbehandlung von Patienten mit primärer glomerulärer Erkrankung in Medikamentöse Therapie bei Nierenerkrankungen. (Georg Thieme, Stuttgart, 1971).

27. MAINTZ, J., ELEMA, J.D., HENNINGSEN, B., BLAKER, F. and BUNGER, P.: Eine Sonderform der chronischen Glomerulonephritis. Dtsch. med. Wschr. 97 : 1527 (1972).

28. Medical Research Council Working Party: Controlled trial of Azathioprine and prednisone in chronic renal disease. Brit. med. J. 2 : 239 (1971).

29. RASTOGI, S.P., HART-MERCER, J. and KERR, D.N.S.: Idiopathic membranous glomerulonephritis in adults. Remission following steroid therapy. Q. I. Med. 38 : 335 (1969).

30. RICH, A.R. : A hitherto undescribed vulnerability of the juxtamedullary glomeruli in lipoid nephrosis. Bull Johns Hpk. Hosp. 100 : 73 (1957).

31. ROBSON, J.S.: The nephrotic syndrome in Renal Disease, 3rd ed. (Blacwell, London, 1972).
32. SMITH, F.G., GONICK, H., STANLEY, T.M. and McINTOSH, R.M.: The nephrotic syndrome. Current concepts. Ann. intern. Med. $76: 463$ (1972).

33. Summary - International workshop on riskbenefit assessment of Cyclophosphamide in renal disease. Kidney Int. 2 : 352 (1972).

34. TRAVIS, L.B., DODGE, W.F., BEATHARD, G.H., SPARGO, B.H., LORENTZ, W.B., CARVAJAL, H.F. and BERGER, M.: Acute glomerulonephritis in children. Clin. Nephrol. $1: 169$ (1973).

35. WHITE, R.H.R., GLASGOW, E.F. and MILLS, R.J.: Clinicopathological study of nephrotic syndrome in Childhood. Lancet 1 : 1353 (1970).

36. WILA WIRYA, I.G.N., BAKRI, F. and HIMAWAN, S.: A clinicopathological correlation of childhood nephrotic syndrome. Paediatr. Indones. (in press). 